\title{
Considering ventilation on demand for the developments of the New Level Mine Project, EI Teniente
}

\author{
El Acuña Codelco, Chile
}

A Feliú Codelco, Chile

\begin{abstract}
The New Level Mine Project (NLMP) underground expansion represents the future of the El Teniente mines in Rancagua, Chile. With the expansion, the daily production rate is expected to be between $137 \mathrm{ktpd}$ and a maximum of $180 \mathrm{ktpd}$. This represents an increase of slightly over 30\% production for the project. The current plan consists of two multi-year development phases from 2012 to 2014 and from 2015 to 2017, with production planned to start in the end of 2017 or early 2018. The underground development of the NLMP starting from both surface and the current underground workings is already underway. However, the limited availability of airflow for development and energy to increase the mine's ventilation for the 2012 to 2014 period motivated the study of ventilation mitigation strategies such as ventilation on demand to determine if it is possible to expand the number of working faces available, in an attempt to optimise the use of the current resources of the project such as energy. The ultimate objective is to accelerate daily development rates, which will produce additional savings and an increase of the value of the New Level Mine project. This paper presents the results of a preliminary study to estimate the cost and benefits of implementing ventilation on demand to increase the number of working faces and their energy efficient operation for the 2012 to 2014 development phase. The mine's current ventilation strategy for the development of the NLMP is presented and used as the baseline to assess ventilation on demand. The results and decision are discussed in terms of the potential additional value generated by implementing the ventilation on demand strategy, considering energy savings, other benefits that are expected and the time required to pay for the initial capital cost.
\end{abstract}

\section{Introduction}

The developments required for the 2012 to 2014 period are critical to achieve the production target of the NLMP. The scheduled developments have to provide access to the different levels, mainly to multiply the working faces in each level for the 2015 to 2018 period. Unfortunately, during the 2012 to 2014 period, the NLMP has planned to develop two main adits from surface to provide intake and exhaust capacity to the project. As a result, the airflow for the 2012 to 2014 period has to be provided by the current El Teniente mines. The airflow available for the NLMP was determined at $189 \mathrm{~m}^{3} / \mathrm{s}$ (400 kcfm) (Llanca et al. 2013). As could be expected, in addition to the limitation on the airflow availability, a conservative limit was defined for the energy availability. Figure 1 presents the location of the current production level and the development area (NLMP).

Given the situation where the project found itself forced to rely on the airflow and energy that could be obtained from the El Teniente Mine ventilation and electrical systems, the NLMP decided to explore alternatives that could allow for a better use of the airflow and the energy during the 2012 to 2014 development phase. On the ventilation side, the alternative that could impact both on airflow and energy use was identified as the ventilation on demand (VOD) strategy, which will be explained in the next section. Based on the potential benefits of reducing the energy consumption, while maintaining or expanding the number of working faces available, the engineering group of the NLMP decided to evaluate the cost of implementing this ventilation strategy and to estimate the benefits within the three year development period, to determine if it was economic to implement it. 


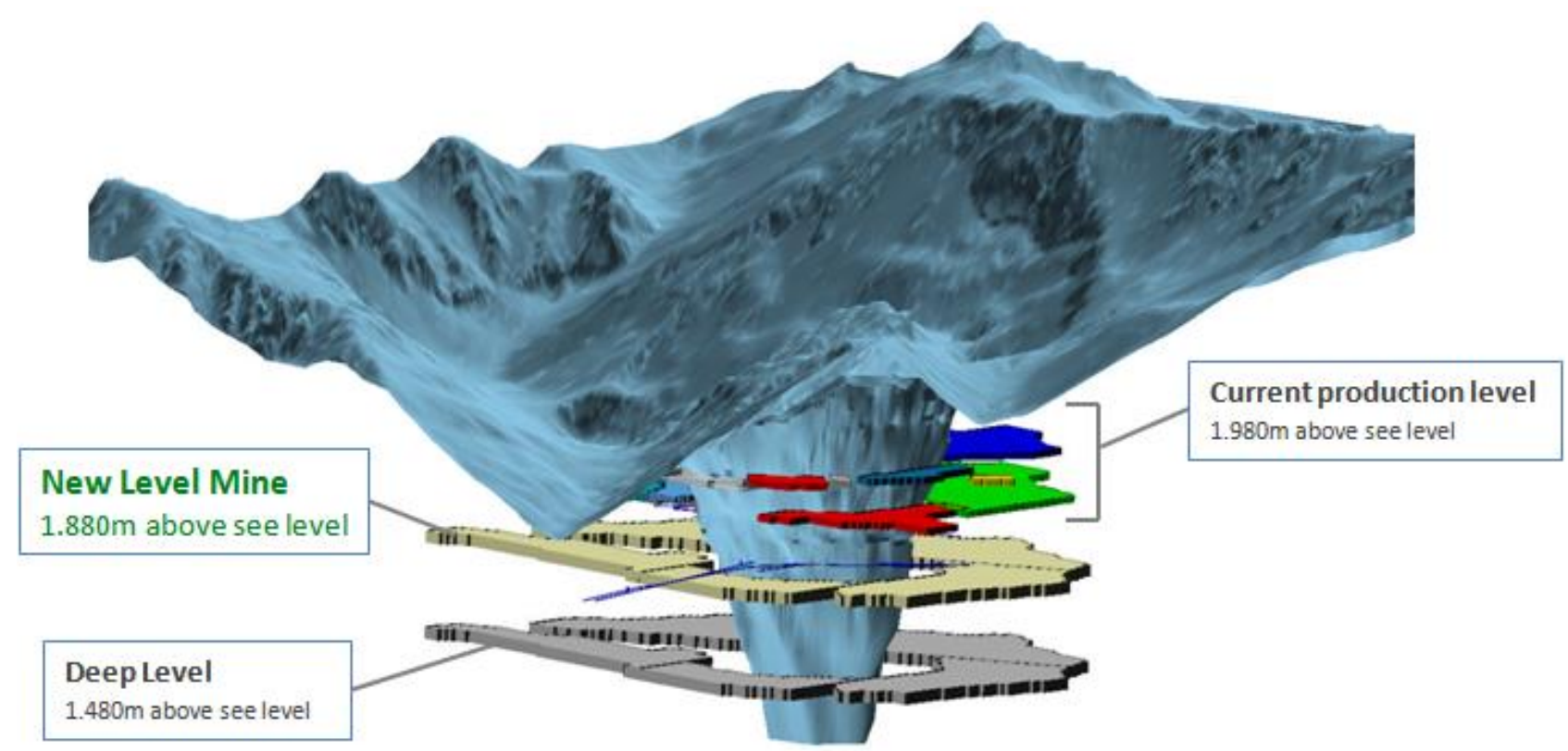

Figure 1 Schematic of current production area and new development area

A VOD strategy not only needs to be economic; it also needs to be implementable within the conditions of the contractors working in the developments. Implementation must not generate an impact or delay on operations that could overcome the expected benefits. The following sections describe the VOD strategy, the benefits, the costs and economical evaluation of the implementation, the considerations and the final decision of the project regarding the implementation for the 2012 to 2014 period.

\section{VOD strategy}

VOD is not a new theme in terms of energy use for ventilation. Recent studies have highlighted the importance of implementing this type of strategy for ventilation management. As indicated by Hardcastle et al. (2006), for $40 \%$ of the total operating time of auxiliary systems, no person or equipment enters the ventilated area or dead end drift, meaning that operating auxiliary ventilation systems requirement could be $40 \%$ less than the current practice. Allen and Keen (2008) and O'Connor (2008), present the potential for implementation in Coleman and Creighton mines respectively, within the Sudbury area in Canada. Allen and Tonnos (2010) and Bartsch et al. (2010), present the implementation of the VOD systems in Coleman and Nickel Rim South mines respectively, both from the Sudbury area. However, the literature available indicates that VOD has only been attempted for production and not development environments.

The VOD strategy is a simple concept that seeks to deliver the required airflow quantity and quality only where and when it is needed to minimise the usage of energy. As an example, the common practice in underground operations is to turn on auxiliary fans systems at the working faces regardless of equipment presence. Turning fans on and off, or modulating their speed through the use of variable frequency drives allows ventilation energy consumption savings for the idle time. The amount of savings will depend on the level of implementation and controls in place. The level of implementation can go from manual to fully automated. The capital cost of implementing and maintaining the VOD system will increase with savings. As a result, an equilibrium point should be reached in terms of level of implementation, savings and costs for each application at each mine.

It is important to note that such ventilation energy savings have no impact in the mine production rates but only a cost reduction. However, as a result of the ability to modulate the airflow usage at the auxiliary or distribution level, and within the constraints of the main system airflow, the use of VOD strategy may allow for more working faces with the same initial available airflow. Simply by better distributing the airflow only to ongoing activities, all the airflow remaining from inactive working faces can be redirected to other 
working faces, potentially allowing an increase in the number of simultaneous working faces. For most development, having some extra airflow available in certain moments due to a control strategy as the VOD will not necessarily result in more working faces, mainly due to the need for more equipment to operate the additional faces. Having a clear understanding of the availability for additional working faces, the costs and the benefits associated are keys to making the decision to implement the VOD strategy. In practical terms and for most development and operation, having the airflow available to secure additional working faces will be of sufficient benefit to outweigh the implementation costs.

\section{Economic evaluation}

The economic evaluation of implementing the VOD strategy was divided into three steps: estimation of benefits, estimation of costs and calculation of the net present value for the three years of the 2012 to 2014 period considered.

\subsection{VOD benefits}

First, to estimate the benefits, the development cycle is introduced detailing each activity, the equipment and ventilation requirement, in order to understand the current need for ventilation and the potential for energy savings related to ventilation.

The development cycle is composed of eight main activities, which are repeated constantly over time, with a time spam theoretically estimated at 17.3 hours. As detailed in Table 1, each activity takes a certain time to be performed, and requires certain pieces of equipment.

\section{Table 1 Activities of the development cycle and airflow requirements}

\begin{tabular}{cccccc} 
Activity & $\begin{array}{c}\text { Time } \\
(\mathbf{m i n})\end{array}$ & $\begin{array}{c}\text { Accumulated } \\
\text { time } \\
(\mathbf{m i n})\end{array}$ & Equipments & $\begin{array}{c}\text { Airflow } \\
\text { required } \\
\left(\mathbf{m}^{3} / \mathbf{s}\right)\end{array}$ & $\begin{array}{c}\text { Airflow } \\
\text { delivered } \\
\left(\mathbf{m}^{3} / \mathbf{s}\right)\end{array}$ \\
\hline $\begin{array}{c}\text { Face drill } \\
\text { Explosive load }\end{array}$ & 116 & 116 & Jumbo drill & 5.4 & 31.4 \\
Blast clearance & 60 & 176 & Manitou & 5.4 & 31.4 \\
Load and haul & 175 & 206 & - & 31.4 & 31.4 \\
Scaling & 30 & 381 & LHD + Truck & 31.4 & 31.4 \\
Shotcrete 1 & 280 & 611 & Jumbo & 5.4 & 31.4 \\
Ground support & 109 & 800 & $\begin{array}{c}\text { Mixer + } \\
\text { Roboshot }\end{array}$ & 11.1 & 31.4 \\
Shotcrete 2 & 241 & 1,041 & Manitou & 5.4 & 31.4 \\
& & Mixer + & 11.1 & 31.4 \\
\hline
\end{tabular}

In order to estimate the airflow requirement, when diesel equipment is involved, the Chilean regulation (Ministerio de Minería 2004) indicates $2.83 \mathrm{~m}^{3} / \mathrm{min} /$ brake horse power (BHP) $\left(0.063 \mathrm{~m}^{3} / \mathrm{s} / \mathrm{kW}\right.$ ), which is equivalent to the $100 \mathrm{cfm}$ per BHP of the Ontario regulation (Ontario Ministry of Labour 2013). Additionally, where personnel are to be working, a minimum velocity of $0.25 \mathrm{~m} / \mathrm{s}$ is required, which is equivalent to $5.4 \mathrm{~m}^{3} / \mathrm{s}$. As a result, three different airflow requirements are needed during the development cycle as indicated in Table 1; 5.4, 11.1 and $31.4 \mathrm{~m}^{3} / \mathrm{s}$. Temperature and dust exposure were not considered to be an issue with the airflow delivered for each activity and procedures in place.

According to Acuña and Lowndes (2014) power requirements are proportional to the cube of the airflow as presented in Equation (1). 


$$
P \approx R \cdot Q^{3}
$$

Where:

$$
\begin{aligned}
& P \quad=\text { power }(\mathrm{kW}) . \\
& R \quad=\text { resistance of the ventilation system }\left(\mathrm{Ns}^{2} / \mathrm{m}^{8}\right) . \\
& Q \quad=\text { airflow }\left(\mathrm{m}^{3} / \mathrm{s}\right) .
\end{aligned}
$$

The energy consumption of a ventilation system is proportional to the power consumption and the length of time the system is running.

The resistance of the auxiliary ducting systems will change over time as the working faces advance, as indicated by Acuña et al. (2010) and Duckworth and Lowndes (2003). Nevertheless, as a first approximation, the savings are only proportional to the airflow requirements as the resistance can be considered constant for any interval period and ventilation system considered. Hence the resulting savings over time will only be a function of the airflow requirement differences.

For the sake of simplicity, only the full requirement of $31.4 \mathrm{~m}^{3} / \mathrm{s}$ and the $11.1 \mathrm{~m}^{3} / \mathrm{s}$ requirement were considered to estimate the potential savings. Equation (2) shows how to calculate the estimated power savings as a function of the airflow requirements in terms of percentage. The theoretical power savings are in the order of $95.6 \%$.

$$
S=1-\left(\frac{11.1}{31.4}\right)^{3}
$$

Where:

$$
S=\text { is the maximum theoretical fraction of savings achievable. }
$$

Figure 2 shows a dashed line representing the airflow delivered by regular practice of turning on fans and never modulating the airflow delivered, and a solid line representing the airflow requirements for each activity according to regulation. The maximum theoretical savings achievable is the energy associated with the area between the two curves. As presented in Equation (2) and due to the cube exponent of the airflow, the expected theoretical savings are far greater than just the difference between the required and the delivered airflow.

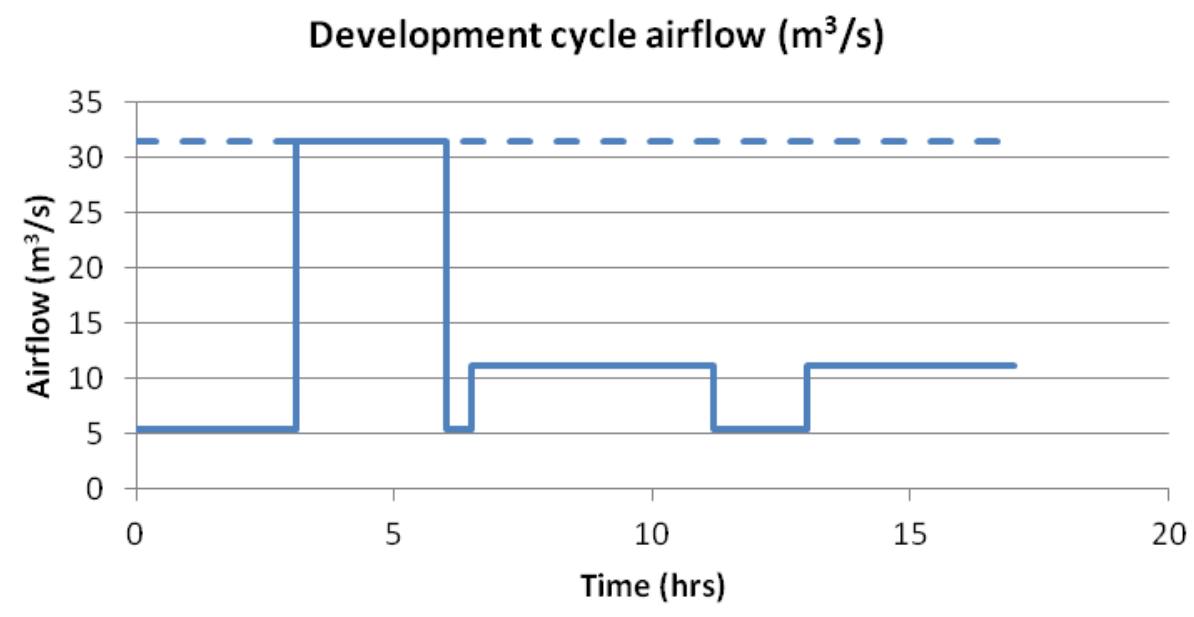

- Airflow required - - Airflow delivered

Figure 2 Estimated required and delivered airflow through development cycle 
The benefit of implementing a VOD strategy was calculated considering a more conservative boundary of $60 \%$. However, in practical terms, even if this estimation is conservative, achieving such savings still remains a challenging target for the considered operation. Also, because of the development program, only two out of the three years were considered for the estimation of benefits, due to the limited drift development and usage of energy during the first year.

The presented estimation is considered very conservative as in any other case where delays are observed between activities resulting from the lack of available supplies, logistic problems or unavailability of equipment, the idle time that has to be included comes at the minimum airflow requirement, which produces larger savings.

Considering $60 \%$ of the energy available for fans during the 2012 to 2014 period, results in savings as presented in Table 2.

Table 2 Savings based on available energy for fans

\begin{tabular}{cccccccc}
\hline & $\begin{array}{c}\text { Power } \\
\text { (kW) }\end{array}$ & $\begin{array}{c}\text { Energy } \\
\text { (kWh/year) }\end{array}$ & $\begin{array}{c}\text { Price 2013 } \\
\text { (USD/kWh) }\end{array}$ & $\begin{array}{c}\text { Price 2014 } \\
\text { (USD/kWh) }\end{array}$ & $\begin{array}{c}\text { Value 2013 } \\
\text { (USD/kWh) }\end{array}$ & $\begin{array}{c}\text { Value 2014 } \\
\text { (USD/kWh) }\end{array}$ & $\begin{array}{c}\text { Total } \\
\text { (USD) }\end{array}$ \\
\hline Available & 1,240 & $10,862,400$ & 0.1534 & 0.1413 & $1,666,292$ & $1,534,857$ & $3,201,149$ \\
Savings (60\%) & 744 & $6,517,440$ & 0.1534 & 0.1413 & 999,775 & 920,914 & $1,920,690$ \\
\hline
\end{tabular}

Table 2 includes energy prices valid at the time of developing this study. As presented in Table 2, the estimated savings for the years 2013 and 2014 are in the order of USD 1.9 million. Table 2 presents the estimation of savings based on power to be used by the fans considered for the developments.

\subsection{VOD costs}

The main costs considered for the VOD system result from the following components:

- Monitoring stations (airflow, temperature, gas sensors).

- Variable frequency drives for fans.

- VOD software and operator.

- Communication network for data between ventilation system components and VOD software.

Initially the system used to locate personnel and equipment, referred to as access control system and personnel and equipment monitoring (ACSPEM), was not considered within the economic evaluation as it was part of the safety features that were going to be required by the development contractor. Another cost to consider is the engineering works required to size and install the VOD system. Table 3 summarises the engineering, supply and installation cost of the 2012 to 2014 period VOD system.

\section{Table 3 Estimated summary cost for 2012 to 2014 period VOD System}

\begin{tabular}{cc}
\hline Item & Cost \\
\hline Engineering & $1,049,000$ \\
Supplies & $1,497,800$ \\
Installation & 92,800 \\
Total (USD) & $2,639,600$ \\
\hline
\end{tabular}

As presented in Table 3, the cost of implementing the VOD system is clearly larger than the expected benefits at $60 \%$ (USD $1.9 \mathrm{~m}$ ). However, if considering the saving at the maximum theoretical achievable of 95.6\% (USD $3 \mathrm{~m}$ ), then the expense of installing and operating the VOD system may be justifiable. 


\subsection{VOD economic evaluation}

The following section develops an estimation of the net present value (NPV). Table 4 presents the estimated NPV of the VOD project for the 2012 to 2014 period. The discount rate used was $8 \%$.

Table 4 Estimated NPV of the VOD project for the 2012 to 2014 period

\begin{tabular}{ccccc}
\hline $\begin{array}{c}\text { Capital cost } \\
\text { (USD) }\end{array}$ & $\begin{array}{c}\text { Cash flow 2012 } \\
\text { (USD) }\end{array}$ & $\begin{array}{c}\text { Cash flow 2013 } \\
\text { (USD) }\end{array}$ & $\begin{array}{c}\text { Cash flow 2014 } \\
\text { (USD) }\end{array}$ & $\begin{array}{c}\text { NPV } \\
\text { (USD) }\end{array}$ \\
\hline$-2,639,600$ & 0 & 999,775 & 920,914 & $-973,520$ \\
\hline
\end{tabular}

As presented in Table 4, the estimated benefits and costs of the project for the 2012 to 2014 period result in a negative NPV of 973,520 USD. As indicated in the benefit section, the 2012 period was considered to not generate meaningful savings. Considering that two years is a short time to retrieve the capital investment, a second NPV calculation was developed assuming that the automated VOD working faces could be used for the second phase of development. Table 5 presents the estimated NPV of the VOD project for the 2012 to 2016 period.

Table 5 Estimated NPV of the VOD project for the 2013 to 2016 period

\begin{tabular}{ccccccc}
\hline $\begin{array}{c}\text { Capital cost } \\
\text { (USD) }\end{array}$ & $\begin{array}{c}\text { Cash flow } 2013 \\
\text { (USD) }\end{array}$ & $\begin{array}{c}\text { Cash flow 2014 } \\
\text { (USD) }\end{array}$ & $\begin{array}{c}\text { Cash flow 2015 } \\
\text { (USD) }\end{array}$ & $\begin{array}{c}\text { Cash flow } 2016 \\
\text { (USD) }\end{array}$ & $\begin{array}{c}\text { NPV } \\
\text { (USD) }\end{array}$ \\
\hline$-2,639,600$ & 999,775 & 920,914 & $1,019,979$ & $1,030,407$ & 595,116 \\
\hline
\end{tabular}

As presented in Table 5, the considered VOD project only becomes attractive at the fourth year of implementation, paying the capital cost during its last year. If the ACSPEM is considered, the costs will increase significantly making the project cost effective only considering a horizon of four to five years.

\section{Considerations to implement VOD}

This section details the considerations and challenges that the El Teniente Mine has to overcome for a successful implementation of a VOD system. Most of the arguments presented in this section apply to both development and production stages, and are particular to El Teniente Mine underground operations. The extension of these arguments to other mines is not straight forward, and should not be done without considering mining method, applicable environment laws, social and cultural environment and other relevant criteria that could influence the operational strategies of the mine.

Current practice at El Teniente Mine is to operate main fans remotely from the Fans and Doors Command Centre (FDCC). Most fans do not have variable frequency drives (VFD) to change fan speed and airflow, and they are always working except when under maintenance, usually once or twice a month. Instrumentation is fitted to fans to monitor operation, vibration and temperature.

El Teniente Mine is composed of several mine sectors big enough to be considered mines and with independent secondary ventilation resources. Secondary fans are operated through localised control centres in each mine, with on-off capacity, but runs $90 \%$ of the available time. As with the main fans, secondary fans are only equipped with vibration and temperature sensors.

El Teniente, has very little environmental sensors as $\mathrm{CO}, \mathrm{NO}$ or $\mathrm{NO} 2$ and $\mathrm{O} 2$ for gases. The effort required to keep them working is considerable in terms of sensors maintenance and providing reliable connectivity to the FDCC. Introducing a massive amount of these sensors to track the environmental conditions within the mine would represent a major step, considering the current practices.

A key input for the implementation of a VOD is to identify the location and number of persons and pieces of equipment distributed within the mine and in the different ventilation zones. A ventilation zone is defined as a geographic area consisting of one or more levels (usually only one) that are ventilated by the action of 
a set of fans, doors and regulators. The system used to locate personnel and equipment is referred to as ACSPEM. The information provided by the ACSPEM has to be integrated with the VOD system as an input and must be very reliable, because these data are keys to the correct operation of the VOD system.

The systems mentioned in the previous paragraphs, the ACSPEM, the FDCC, gas monitoring and other systems, have to transmit data through the Control Supervision Integrated Network (CSIN), which enables Ethernet connectivity (optics, wired and wireless) using TCP/IP protocols.

The cultural change within the user of the system is probably the biggest challenge. As the system will only work if the users are convinced that it will improve their safety and make the underground environment where they are working healthier. A communication effort must be put in place to transmit the benefits of the VOD system based on the quality and the competiveness that this kind of system can provide to the El Teniente Mine and its workforce. At the workforce level this will probably require an agreement with the different unions of the mine.

New technology usually comes with the challenge of making it accepted within the workforce, mainly through demonstrating that it is suitable for the operation and personnel. The best strategy is probably to focus on a small pilot to demonstrate effectiveness and efficiency, and then expand to the other operations. However, VOD also requires other system to be implemented and integrated as the sensors, the ACSPEM and the FDCC to the CSIN. The integration of these systems makes it a larger, but necessary step for decreasing the operational costs of the mine.

New technology not only comes with a challenge in terms of acceptance, but also with the learning curve challenge. Users have to learn the new way of operating and to troubleshoot the system and get it back to work as soon as possible in a failure case. The learning period is usually painful and normally impacts the development rates in a negative manner. Having a contractor as the first to implement such a VOD system in a dynamic development environment raises the questions about how long it will take to reach a stable state (finish the learning curve) and how will it impact the expected development rates.

Besides the factors already mentioned some particular ones apply for implementing VOD within a development environment and are detailed as follows:

- Fast advance and multiplication of working faces (auxiliary system).

- Changing main ventilation system (new raises and fans).

Unlike a production environment, where the number of draw points is sized to the daily production of the mine, making it somehow stable through time, the developments of the NLMP considers the increase of the number of working faces from a few current ones to four maybe five times the ongoing number today. In addition to the increase in the number of working faces, the available working faces will change over time, meaning that the total number of development faces will remain the same, but with different locations in time according to the development program. These two changes, number and location of working faces, requires dynamic auxiliary systems to support the personnel and diesel equipment. To consider moving the VOD infrastructure for each auxiliary system requires a significant logistic and specialists effort.

The dynamism of the auxiliary system in the particular case of the NLMP comes coupled with changes in the main system used to provide the airflow to the auxiliary systems. The NLMP has considered the development of at least 19 raises to connect to El Teniente Mine and to circulate $189 \mathrm{~m}^{3} / \mathrm{s}(400 \mathrm{kcfm})$, through the main system available for 2012 to 2014 developments. As these raises are put in place, the airflow available through the system increases and the airflow distribution between intake and exhaust also changes. At least five stages of the main ventilation system have been identified during the 2012 to 2014 development phase. Implementing the VOD infrastructure as each new raise is developed and each new ventilation system is installed also requires significant logistic and specialists effort.

Considering all the factors provided in this section, which are not easy to quantify in terms of cost, benefit or time required to implement, and also taking into account the dynamic environment of developments, 
the NLMP decided not to implement the VOD strategy for the two development phases considered (2012 to 2014; and 2015 to 2017) to start production. The main concern was burdening the contractor with responsibility for the implementation, commissioning, maintenance and displacement of the numerous systems that have to work together, and the resulting impact this could have had on the expected date to start production. As a result, the NLMP decided to postpone the implementation of VOD strategy for the production phase.

With the current capacities and knowledge of the contractor companies available it is potentially possible to implement the VOD for developments, however, this would require the combined work of an automation and control contractor and a construction contractor, which historically have not work together in the same area at the same time. Usually the construction contractor develops the drifts and raises and then the automation and control contractor implement the infrastructure with a definitive design and not a temporal subject to change in a very short span of time to follow up development. Having both contractors working together will generate interferences and delays which will probably result to be more expensive for the New Level Mine Project than the savings in energy that a VOD strategy could generate over a few years of implementation. Also to have both contractors working together requires an important change in the working culture of both contractors which will not be easily achieved, even less considering the pressure to achieve the meter target of the developments.

Surprisingly, but forced by the current cross sections (which limit the number and size of ducting that can be used) and equipment availability, contractors have started to consider and propose manual VOD strategies to make a better use of the airflow resources within the different levels they are developing, in order to make a better use of their pieces of equipment without having to introduce larger and more powerful ventilation systems for both the main and auxiliary systems. However, in practical terms, this will require considerable supervision of the contractor practices and considering a central control room for the auxiliary and booster fans.

\section{Conclusions}

A preliminary study was conducted to determine the economic value of implementing a VOD strategy for the 2012 to 2014 developments. The results indicated that within the data available, it was cost effective to implement such strategy just considering the energy savings that could be generated and the cost of the infrastructure that has to be put in place. The preliminary results of this study indicated that implementing a VOD strategy for the NLMP developments has a payback period of four years without considering the ACSPEM system, and would probably extend to or over five years if this system had to be consider as part of the initial investment. However, obtaining preliminary profitable numbers is not the only requirement to push forward an innovative initiative. Several non measurable aspects were estimated to have a negative impact towards the implementation of the VOD strategy and the expected developments of the 2012 to 2014 period. Among the negative aspects, the ones that could impact most significantly the developments are the implementation of a new process and its learning curve, the complexity of keeping up with the changes of the working faces and maintaining operational an additional control system within a dynamic development environment. As a result, in order to minimise any potential impact to the scheduled developments of the 2012 to 2014 period, and given the criticality of the current developments for the next phase of the developments and to achieve production, the NLMP decided not to implemented the VOD strategy for the development phase and to postpone its implementation for the operation phase. According to the experience of the NLMP engineers a production environment is more stable than the contractor developments and it is also operated by in house personnel, making it more suitable for the implementation of an energy saving project such as the VOD.

\section{References}

Acuña, El \& Lowndes, IS 2014, 'A review of primary mine ventilation system optimization', Interfaces, vol. 44, no. 2, pp.163-175. Acuña, El, Hardcastle, S, Fava, L \& Hall, S 2010, 'The application of a MIP model to select the optimum auxiliary fan and operational settings for multiple period duties', INFOR, vol. 48, no. 2, pp. 89-96. 
Allen, C \& Keen, B 2008, 'Ventilation on demand (VOD) project - Vale Inco Limited, Coleman Mine', in KG Wallace (ed.), Proceedings of the 12th US Mine Ventilation Symposium, University of Nevada, Reno, pp. 45-50.

Allen, C \& Tonnos, AM 2010, 'Ventilation control system implementation model at Vale Inco mines: pilot at Coleman Mine', in S Hardcastle \& DL McKinnon, Proceedings of the 13th US Mine Ventilation Symposium, MIRARCO, Sudbury, pp. 159-162.

Bartsch, E, Laine, M \& Andersen, M 2010, 'The application and implementation of optimized mine ventilation on demand (OMVOD) at the Xstrata Nickel Rim South Mine, Sudbury, Ontario', in S Hardcastle \& DL McKinnon, Proceedings of the 13th US Mine Ventilation Symposium, MIRARCO, Sudbury, pp. 171-179.

Ministerio de Minería 2004, Reglamento de Seguridad Minera: Decreto Supremo N²132, chapters 3 and 4, pp. 46-51, viewed 7 August 2014, http://www.sernageomin.cl/pdf/mineria/seguridad/reglamentos_seguridad_minera/ DS132_Reglamento_SEGMIN.pdf, (in Spanish).

Duckworth, IJ \& Lowndes, IS 2003 'Modelling of auxiliary ventilation systems', Mining Technology, vol. 112, no. 2, pp. $105-113$.

Hardcastle, SG, Kocsis, C \& O'Connor, D 2006, 'Justifying ventilation on demand in a Canadian mine and the need of process based simulations', in JM. Mutmansky \& RV Ramani (eds), Proceedings of the 11th US Mine Ventilation Symposium, Taylor \& Francis Group, London, pp. 15-27.

Llanca, JL, Hurtado, JP \& Acuña, El 2013, 'CFD Analysis of the main fan parallel installation for the 2012-2014 underground developments of the New Level Mine Project', Proceedings of the 23rd World Mining Congress, Canadian Institute of Mining, Metallurgy and Petroleum, Westmount.

O'Connor, DF 2008, 'Ventilation on demand (VOD) auxiliary fan project - Vale Inco Limited, Creighton Mine', in KG Wallace (ed.), Proceedings of the 12th US Mine Ventilation Symposium, University of Nevada, Reno, pp. 41-44.

Ontario Ministry of Labour 2013, R.R.O. 1990, Regulation 854, Mines and Mining Plants, Section 183.1 (3), viewed 7 August 2014 , http://www.e-laws.gov.on.ca/html/regs/english/elaws_regs_900854_e.htm 
